\title{
A Scanning Electron Microscopic Study on Effect of Blood and Artificial Salivary Contamination on Marginal Adaptation of Mineral Trioxide Aggregate, When Used as a Retrograde Filling Material: An In Vitro Study
}

\author{
Anuja Mody ${ }^{1}$, Ruchi Arora ${ }^{2}$, Prabhav Chauhan ${ }^{3}$, Kompal Gautam $^{4}$, Pratibha Taneja ${ }^{5}$, CM Marya ${ }^{6}$
}

\begin{abstract}
Aim and objective: The present study was conducted to evaluate the marginal adaptability of mineral trioxide aggregate (MTA) as a root-end filling material when manipulated using two different IV fluids intended for pediatric usage; in the presence of blood and salivary contamination. Materials and methods: Sixty single-rooted teeth were selected. Conventional endodontic root canal preparation was performed on all specimens followed by root-end resection and retrograde cavity preparation. The roots were randomly divided into two groups ( $n=30$ ). In the specimens of group I, fresh blood was used as a contaminant and in group II artificial saliva was used as a contaminant. In both groups, MTA (e-MTA, Kids-e-Dental ${ }^{\oplus}$ ) manipulated using either Ringer's lactate IV fluid ( $\left.n=15\right)$ or Tetraspan IV fluid $(n=15)$ was used for root-end filling in blood or artificial saliva-coated retrocavities. Furthermore, these roots were placed in beakers pooled with fresh phlebotomized blood or artificial saliva. After incubating for 48 hours, the roots were divided longitudinally to expose the retrofilled cavities and were then sputtercoated with gold-platinum dust. To assess the marginal adaptation of MTA to radicular dentin "maximum gap width" and "gap perimeter" were measured in images obtained from scanning electron microscopy of root specimens. SPSS 21 was employed for statistical analysis at $(p<0.05)$. Mann-Whitney $U$ test and ANOVA were used for analyzing the data obtained.

Results: The gap width was more among samples exposed to blood $(p<0.05)$ than artificial saliva. No significant difference was reported in the gap perimeter when cavities were filled with MTA mixed with either IV fluids $(p>0.05)$.

Conclusion: Exposure to blood during setting had a negative effect on gap width when retrocavities were filled with MTA using Tetraspan. No effect was seen on the arch perimeter in retrocavities filled with MTA mixed with Ringer's lactate or Tetraspan.

Clinical significance: For avoiding failure, it is critical to select a biocompatible root-end filling material with high sealing ability. Hence, by doing the same, the clinical situation can be simulated.

Keywords: Biocompatibility, Intravenous fluids, Mineral trioxide aggregate, Retrograde filling.

International Journal of Clinical Pediatric Dentistry (2021): 10.5005/jp-journals-10005-2012
\end{abstract}

\section{INTRODUCTION}

Mineral trioxide aggregate (MTA), introduced by Mahmoud Torabinejad in 1993 is a biocompatible class II medical device for root canal filling as recommended by the US-FDA. It was initially available as a gray variety and later a tooth-colored version commonly referred to as "white MTA" was available from 2002 onward. $^{1-3}$

Over the years, research on MTA has made its application possible in various clinical situations like pulp therapy, apexification, bleaching of discolored teeth, repairing vertical root fractures, root perforations, and resorptive defects; orthograde root canal filling in addition to its use as a suitable root-end filling material. ${ }^{4,5}$

Among a glut of retrograde filling materials like GIC, amalgam, composite resin, and others, MTA has shown the most promising results owing to its biocompatibility, ability to form a mineralized tissue barrier, less apical leakage, enhanced marginal adaptation, and the unique possibility of being used in a humid environment. ${ }^{1,5,6}$

Another less than ideal property of MTA is its handling characteristics. According to the manufacturer's recommendations, when MTA is manipulated using sterile water, it produces a grainy, sandy mixture making its compaction and delivery to the required site cumbersome. To overcome this limitation, common reagents like chlorhexidine gluconate, local anesthesia solution, calcium
${ }^{1}$ Department of Pediatric and Preventive Dentistry, Private Practice, Prabhadevi, Worli, Mumbai, Maharashtra, India

${ }^{2}$ Department of Pediatric and Preventive Dentistry, Darshan Dayal Dental College and Hospital, Loyara, Udaipur, Rajasthan, India

${ }^{3}$ Department of Pediatric and Preventive Dentistry, Private Practice, Greater Noida, Uttar Pradesh, India

${ }^{4}$ Department of Periodontology and Implantology, Siyaram Hospital, Jaipur, Rajasthan, India

${ }^{5}$ Department of Public Health Dentistry, Private Practice, Gurugram, Haryana, India

${ }^{6}$ Department of Public Health Dentistry, Sudha Rustagi College of Dental Science and Research, Faridabad, Haryana, India

Corresponding Author: Pratibha Taneja, Department of Public Health Dentistry, Private Practice, Gurugram, Haryana, India, Phone: +91 7982786391, e-mail: pratibhataneja3@gmail.com

How to cite this article: Mody A, Arora R, Chauhan P, et al. A Scanning Electron Microscopic Study on Effect of Blood and Artificial Salivary Contamination on Marginal Adaptation of Mineral Trioxide Aggregate, When Used as a Retrograde Filling Material: An In Vitro Study. Int J Clin Pediatr Dent 2021;14(5):674-680.

Source of support:

Conflict of interest:

() The Author(s). 2021 Open Access This article is distributed under the terms of the Creative Commons Attribution 4.0 International License (https://creativecommons. org/licenses/by-nc/4.0/), which permits unrestricted use, distribution, and non-commercial reproduction in any medium, provided you give appropriate credit to the original author(s) and the source, provide a link to the Creative Commons license, and indicate if changes were made. The Creative Commons Public Domain Dedication waiver (http://creativecommons.org/publicdomain/zero/1.0/) applies to the data made available in this article, unless otherwise stated. 
chloride, etc., have been proposed as additives for MTA. ${ }^{7}$ In a clinical setting, saline is often used to manipulate MTA when sterile water is not available or exhausted. Similarly, Ringer's lactate and Tetraspan are commonly available intravenous fluids in a pediatric health care setup. To our knowledge, both Ringer's lactate and Tetraspan IV fluids have never been used to reinforce MTA. Hence, these two IV fluids were tested in the present study to manipulate MTA.

In most clinical situations while performing a root end surgery, MTA comes directly in contact or may be mixed with blood, saliva, or tissue fluids leading to biologic contamination. ${ }^{8}$ Thus, the present study aimed to check the effect of blood and artificial salivary contamination on marginal adaptability of MTA as a retrograde filling material, when MTA was manipulated using Ringer's lactate and Tetraspan IV fluids.

\section{Materials and Methods}

The present study was carried out in the Department of Pedodontics and Preventive Dentistry, Darshan Dental College and Hospital, Udaipur in accordance with Analytical Chemistry Department at Bhabha Atomic Research Centre, Mumbai after obtaining institutional ethical clearance.

Sixty fully developed, freshly extracted, caries-free human teeth were selected. Periodontally compromised, single-rooted intact teeth without fracture or craze lines and fully developed apices were included, whereas teeth having cervical caries or developmental anomalies, immature or fractured teeth, and deciduous teeth were excluded from this study.

In our study, the technique adopted from Milani et al. ${ }^{7}$ was followed. After clearing teeth of extrinsic stains, debris, blood, or saliva, they were stored in $5 \%$ sodium hypochlorite for a week and then in saline until use. Decoronation was done up to the CEJ and the working length of roots was determined $0.5 \mathrm{~mm}$ short of the total root length or when a $2 \%$ stainless steel \#15 K-file was visible at the apical foramen of the root. Chemico-mechanical preparation of the roots was performed up to \#40 and step-back preparation was done up to \#70 K-file with copious $5 \% \mathrm{NaOCl}$ and saline irrigation. The root canals were dried, coated with a sealer, and obturated using gutta-percha points.

Then, apical $3 \mathrm{~mm}$ root resection was performed using a diamond disk followed by apical $3 \mathrm{~mm}$ retrograde cavity preparation with conventional round burs. The roots were coated with two layers of acid-resistant nail varnish except for the resected root-end surface. The roots were then divided into group I and group II where MTA (e-MTA, Kids-e-Dental) was exposed to fresh phlebotomized blood obtained from the first author, and artificial salivary contamination, respectively; and further subdivided as group IA (MTA + Ringer's lactate), group IB (MTA + Tetraspan), group IIA (MTA + Ringer's lactate), and group IIB (MTA + Tetraspan) where MTA was manipulated using either Ringer's lactate or Tetraspan IV fluids. These roots were placed in a glass beaker containing fresh blood or artificial saliva depending on the groups to which they belonged. The roots were then incubated at $37^{\circ} \mathrm{C}$ and $100 \%$ relative humidity for 48 hours. Later, roots were resected longitudinally, parallel to their long axes, and transported in air-tight containers for SEM analysis.

Root specimens were placed on an aluminum stub and sputtered with gold-platinum dust under ion-beam sputtering (Quorum Technologies ${ }^{\circledR}$, Kent) and further subjected to an electron projection chamber for scanning electron microscopy (Vega3 TESCAN ${ }^{\circledR}$, Czech Republic).
To assess the marginal adaptation of MTA to dentine, the following variables were measured by a blind observer:

\section{Maximum Gap Width}

This was the maximum distance between MTA and cavity walls measured directly at MTA-dentine interface at magnification $(\times 400$ to $\times 2200 \mu \mathrm{m}$ ).

\section{Gap Perimeter Analysis}

"Gap Perimeter" was measured as the ratio of the gap perimeter to the perimeter of retrocavity margin at magnification $(\times 100$ to $\times 600$ $\mu \mathrm{m})$ and was rated on a score criterion as follows:

Score 1: Less than or equal to $1 / 4$ of the cavity margin.

Score 2: More than $1 / 4$ but less than or equal to $1 / 2$ of the cavity margin. Score 3: More than $1 / 2$ but less than or equal to $3 / 4$ of cavity margin. Score 4: More than $3 / 4$ of the cavity margin.

\section{RESULTS}

Data were analyzed using Statistical Package for Social Sciences (SPSS) version 21, IBM Inc. Descriptive statistics such as mean, median, and standard deviation for continuous variables and frequency along with percentages of categorical variables were calculated. Mann-Whitney $U$-test checked the maximum gap width between MTA-blood and MTA-artificial saliva interface and ANOVA was used for comparing two groups. A Chi-square test was employed to test the gap perimeter between the two groups. A level of $p<0.05$ was considered statistically significant.

Maximum gap width and gap perimeter were found to be significantly higher in blood-contaminated specimens (Figs 1 and 2) when compared with artificial saliva-contaminated specimens (Figs 3 and 4).

In Table 1, when intragroup comparison for maximum gap width was made, retrocavities filled with MTA-Tetraspan IV fluid showed a significantly higher gap width than MTA-Ringer's lactate IV fluid. In Table 2, when intragroup comparison for gap perimeter was made, both groups had a similar gap perimeter score with a non-significant statistical difference.

However, in Tables 3 and 4, when intergroup comparison was made for maximum gap width; retrocavities filled with MTA-

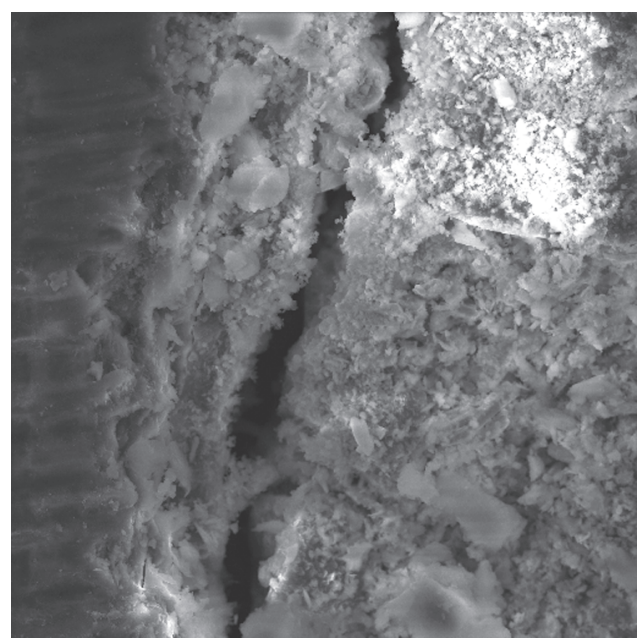

Fig. 1: SEM image shows the marginal gap at the MTA-dentine interface when MTA was manipulated using Ringer's lactate IV fluid in presence of blood contamination 
Tetraspan IV fluid in the presence of blood contamination showed the highest gap width when compared with all other groups.

\section{Discussion}

The primary aim of conventional root canal treatment is the elimination and future exclusion of all microorganisms from the root canal. However, if conventional root canal treatment is impossible or has failed an alternative approach like periapical surgery is necessary which entails apicectomy and retrograde filling. ${ }^{9}$ The first report of such a procedure appears to be made by a French-man Desirabode in $1843 .{ }^{10,11}$

The endodontic periapical surgery embraces exposure, resection of root apex, preparation of root end cavity, and insertion of root-end filling material. ${ }^{12,13}$ Coupled with magnification through surgical operating microscopes, refined principles of soft and hard tissue management, use of tissue regenerative root-end filling materials, enhanced wound closure, and postoperative management; surgical endodontics has emerged as a highly predictable and relatively painless procedure. ${ }^{14}$

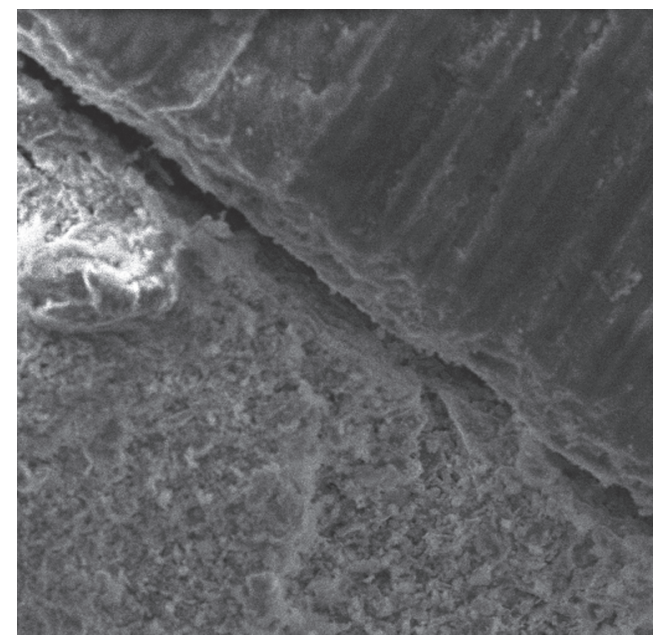

Fig. 3: SEM image shows the marginal gap at the MTA-dentine interface when MTA was manipulated using Ringer's lactate IV fluid in presence of artificial salivary contamination

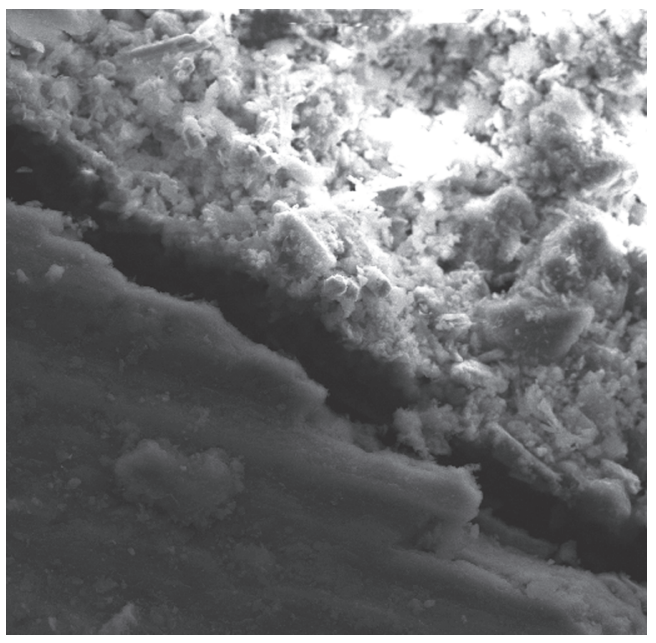

Fig. 2: SEM image shows the marginal gap at the MTA-dentine interface when MTA was manipulated using Tetraspan IV fluid in presence of blood contamination

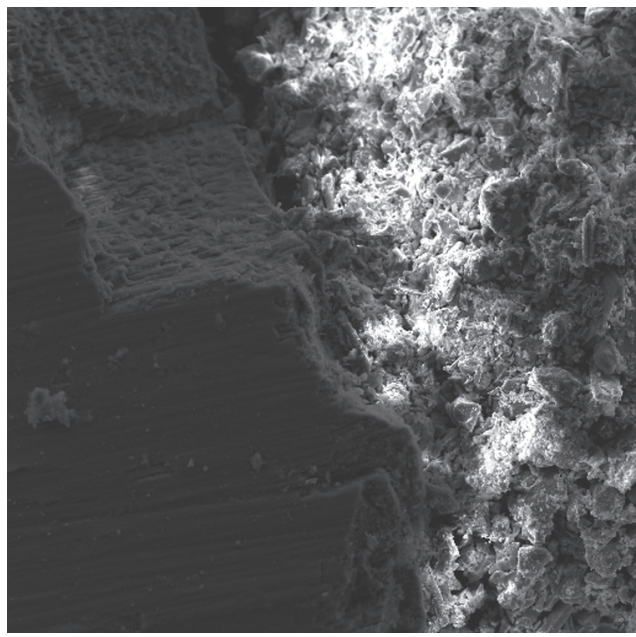

Fig. 4: SEM image shows the marginal gap at the MTA-dentine interface when MTA was manipulated using Tetraspan IV fluid in the presence of artificial salivary contamination

Table 1: Intragroup comparison of maximum gap width when cavities were filled with MTA mixed using Ringer's lactate and Tetraspan intravenous fluids

\begin{tabular}{|c|c|c|c|c|c|c|c|}
\hline \multicolumn{8}{|c|}{ Maximum gap width } \\
\hline \multicolumn{2}{|c|}{ Groups } & \multirow{2}{*}{$\frac{N}{15}$} & \multirow{2}{*}{$\frac{\text { Mean }}{2.34}$} & \multirow{2}{*}{$\begin{array}{l}\text { Standard deviation } \\
1.48\end{array}$} & \multirow{2}{*}{$\frac{\text { Median (IQR) }}{2.88(3.98)}$} & \multirow{2}{*}{$\begin{array}{l}\text { Standard error mean } \\
0.38\end{array}$} & \multirow{2}{*}{$\frac{p \text { value }}{0.461}$} \\
\hline Group IA & Group I & & & & & & \\
\hline Ringer's lactate IV fluid & $\begin{array}{l}\text { Exposed to blood } \\
\text { contamination }\end{array}$ & & & & & & \\
\hline Group IIA & Group II & 15 & 2.01 & 0.82 & $1.89(2.77)$ & 0.21 & \\
\hline Ringer's lactate IV fluid & $\begin{array}{l}\text { Exposed to artificial } \\
\text { saliva contamination }\end{array}$ & & & & & & \\
\hline Group IB & Group I & 15 & 4.00 & 1.60 & $3.99(5.10)$ & 0.41 & $0.016^{*}$ \\
\hline Tetraspan IV fluid & $\begin{array}{l}\text { Exposed to blood } \\
\text { contamination }\end{array}$ & & & & & & \\
\hline Group IIB & Group II & 15 & 2.53 & 1.08 & $2.65(3.69)$ & 0.27 & \\
\hline Tetraspan IV fluid & $\begin{array}{l}\text { Exposed to artificial } \\
\text { saliva contamination }\end{array}$ & & & & & & \\
\hline
\end{tabular}

*Statistically significant 
Table 2: Intragroup comparison of gap perimeter scores when cavities were retrofilled with MTA mixed with Ringer's lactate and Tetraspan intravenous fluids

\begin{tabular}{|c|c|c|c|c|c|c|c|}
\hline \multicolumn{8}{|c|}{ Gap perimeter scores } \\
\hline \multicolumn{2}{|c|}{ Groups } & $N$ & Mean & Standard deviation & Median (IQR) & Standard error mean & $p$ value \\
\hline Group IA & Group I & 15 & 1.66 & 0.81 & $1.00(2.00)$ & 0.21 & 0.808 \\
\hline Ringer's lactate IV fluid & $\begin{array}{l}\text { Exposed to blood } \\
\text { contamination }\end{array}$ & & & & & & \\
\hline Group IIA & Group II & 15 & 1.73 & 0.79 & $2.00(2.00)$ & 0.20 & \\
\hline Ringer's lactate IV fluid & $\begin{array}{l}\text { Exposed to artificial } \\
\text { saliva contamination }\end{array}$ & & & & & & \\
\hline Group IB & Group I & 15 & 2.40 & 0.82 & $2.00(3.00)$ & 0.21 & 0.412 \\
\hline Tetraspan IV fluid & Exposed to blood & & & & & & \\
\hline Group IIB & Group II & 15 & 2.13 & 0.91 & $2.00(3.00)$ & 0.23 & \\
\hline Tetraspan IV fluid & $\begin{array}{l}\text { Exposed to artificial } \\
\text { saliva }\end{array}$ & & & & & & \\
\hline
\end{tabular}

Table 3: Intergroup comparison of maximum gap width in groups I and II

\begin{tabular}{|c|c|c|c|c|}
\hline \multicolumn{5}{|c|}{ Maximum gap width } \\
\hline & Groups & $N$ & Mean & Standard deviation \\
\hline Group IA, IIA & Group I & 15 & 2.34 & 1.48 \\
\hline \multirow[t]{3}{*}{ Ringer's lactate IV fluid } & Exposed to blood contamination & & & \\
\hline & Group II & 15 & 2.01 & 0.82 \\
\hline & Exposed to artificial saliva contamination & & & \\
\hline Group IB, IIB & Group I & 15 & 4.00 & 1.60 \\
\hline \multirow[t]{3}{*}{ Tetraspan IV fluid } & Exposed to blood contamination & & & \\
\hline & Group II & 15 & 2.53 & 1.08 \\
\hline & Exposed to artificial saliva contamination & & & \\
\hline Total & & 60 & 2.72 & 1.46 \\
\hline$p$ value & & \multicolumn{3}{|c|}{$0.006^{*}$} \\
\hline Post hoc pairwise comparison & & \multirow{2}{*}{\multicolumn{3}{|c|}{$3>4>1>2$}} \\
\hline$(I I A>I I B>I A>I B)$ & & & & \\
\hline
\end{tabular}

*Statistically significant

Table 4: Intergroup comparison of gap perimeter scores in groups I and II

\begin{tabular}{|c|c|c|c|c|}
\hline \multicolumn{5}{|c|}{ Gap perimeter scores } \\
\hline & Groups & $N$ & Mean & Standard deviation \\
\hline Group IA, IIA & Group I & 15 & 1.66 & 0.8165 \\
\hline \multirow[t]{3}{*}{ Ringer's lactate IV fluid } & Exposed tc & & & \\
\hline & Group II & 15 & 1.73 & 0.7988 \\
\hline & Exposed tc & & & \\
\hline Group IB, IIB & Group I & 15 & 2.40 & 0.8281 \\
\hline \multirow[t]{3}{*}{ Tetraspan IV fluid } & Exposed tc & & & \\
\hline & Group II & 15 & 2.13 & 0.9155 \\
\hline & Exposed tc & & & \\
\hline Total & & 60 & 2.72 & 0.8732 \\
\hline$p$ value $0.072 \mathrm{NS}$ & & & & \\
\hline
\end{tabular}

In our study, root-end resection was performed using a diamond disk perpendicular to the long axes of the tooth followed by retrograde cavity preparation using a round bur in a high-speed, water-cooled airotor hand piece until a depth of $3 \mathrm{~mm}$ was achieved, in accordance with Gilheany et al. ${ }^{15}$ and Bates et al. ${ }^{16}$ who suggested that depth of retrograde filling and angle of resection are two important factors in direct control of the operator. Increased depth of retrograde preparation reduces apical microleakage and can be related to the fact that placement of a root-end filling material in a deeper cavity occludes many open apical dentinal tubules that are available for the passage of apical fluid. According to Gagliani et al. ${ }^{17}$ and Malhotra and Hegde, ${ }^{18}$ teeth should be apicectomized at $90^{\circ}$ to their long axes and at a depth of $3 \mathrm{~mm}$ to exclude the presence of variations in root anatomy, lateral canals, and apical ramifications. 
Until now many authors including Torabinejad et al., ${ }^{19}$ Bates et al., ${ }^{16}$ and Shipper et al. ${ }^{8}$ have performed various in vitro and in vivo studies to conclude the use of MTA as a superior root-end filling material as compared to others. Hence, we chose MTA as the retrograde filling material. MTA was originally manufactured as Gray MTA but in 2002, a white-cream variation of the original formula of gray MTA was introduced as "white MTA". ${ }^{20}$

Mineral trioxide aggregate contains fine hydrophilic particles primarily of $75 \mathrm{wt} \%$ Portland cement, $20 \mathrm{wt} \%$ bismuth oxide, and $5 \mathrm{wt} \%$ calcium sulfate dehydrate or gypsum. ${ }^{21}$ Belio-Reyes et al. ${ }^{22}$ characterized crystalline minerals in MTA to be Bismite (19.8\%), Haturite (51.9\%), Larnite (23.2\%), tricalcium aluminate (3.8\%), and anhydrite (1.3\%); and other trace elements like iron, nickel, copper, and strontium. Mineral trioxide aggregate is supplied as a powderliquid package, which consists of MTA powder packed in individual pouches and sterile water packed in ampoules. Mineral trioxide aggregate should be prepared immediately before use. The powder should be stored in tight lid containers to prevent hydration. ${ }^{20}$

To date, many fluids like saline, local anesthetic solution, chlorhexidine, and sodium hypochlorite have been advocated to manipulate MTA for improving its working properties. The sterile water supplied with MTA often gets exhausted before the powder. Hence, in clinical settings, convenient and readily available fluids like saline, calcium chloride, sodium hypochlorite in liquid and gel form, KY jelly, and sterile local anesthetic solution are often mixed with MTA powder when sterile water is not available. ${ }^{23,24}$

In our study, Ringer's lactate and Tetraspan intravenous fluids have been used to manipulate MTA. The reason being that, in a Pediatric Healthcare setup, Ringer's lactate, and Tetraspan are safe, easily available, and the IV fluids of choice for fluid resuscitation in children and young adults since they belong to the categories of crystalloids and colloids. ${ }^{25,26}$

We checked marginal adaptation of MTA to radicular dentine in presence of blood and artificial salivary contamination. Blood and artificial salivary contamination were simulated because while performing periradicular surgery, root-end filling materials come directly in contact with these contaminants in virtual, specific clinical conditions. ${ }^{22}$ Blood and artificial saliva were not wiped off the retrocavity walls to simulate worst clinical situations when MTA may get directly mixed or wiped off by these contaminants due to hemorrhage. The presence of such contaminants hampers the sealing ability of root-end filling materials.

The quality of apical seal obtained by retrograde filling materials has been assessed earlier using various methodologies. ${ }^{27-30}$ However, all these techniques require the destruction of study samples to obtain measurements of leakage, thereby precluding measurements of changes in the apical seal over time in individual samples and indicate non-quantitative leakage. To overcome this disadvantage, Orucoglu et al. ${ }^{28}$ introduced a computerized fluid filtration method to assess apical leakage.

But over the years, SEM images have played an important role in evaluating marginal adaptation of various retrograde filling materials. While viewing biological specimens under SEM, they need to be coated with a noble metal to reduce their conductivity and form high-resolution images. Clay et al. ${ }^{31}$ stated that ion beam sputtering, deposits metals onto specimens and eliminates surface artifacts seen at high magnifications. Also, ion beam sputtering does not expose the specimen to a hot source, thus preventing its destruction due to heat. ${ }^{32}$
In the present study, images obtained from SEM assessed marginal adaptation of MTA to radicular dentine. Our idea of using SEM correlated well with Torabinejad et al. ${ }^{12}$ who also used SEM to investigate the marginal adaptation of root-end filling materials and concluded that MTA and amalgam had fewer gaps than SuperEBA and IRM.

In our study, we used "maximum gap width" and "gap perimeter" as variables to assess the marginal adaptation of set MTA to radicular dentine. "Maximum gap width" was the maximum distance between MTA and retrocavity walls and "Gap Perimeter" was the ratio of the gap perimeter of MTA to the perimeter of the retrocavity margin calculated as scores designated between 1 and 4. This was similar to the scoring method used by Milani et al. ${ }^{8}$ who evaluated the effect of exposure of blood on marginal adaptation of MTA.

When the "gap perimeter" was analyzed both, MTA manipulated using Ringer's lactate and Tetraspan IV fluid adapted equally well to root dentine in the presence of blood and artificial saliva.

When "maximum gap width" among retrograde filling and dentine was evaluated, it was observed that the presence of blood led to the formation of higher gap widths at the MTA-dentine interface when both IV fluids were used. This inferred that MTA manipulated using Tetraspan and Ringer's lactate IV fluids had a negative effect on marginal adaptation in the presence of blood, the former being more defying than the latter.

However, MTA manipulated using Ringer's lactate IV fluid had a positive effect on marginal adaptation to radicular dentine than MTA manipulated using Tetraspan IV fluid in presence of artificial salivary contamination.

The possible reason for this could be that in the presence of fluids like blood and artificial saliva, the hydration behavior of MTA was adversely affected and this interfered with MTA's crystallization. ${ }^{25}$ According to Sarkar et al., ${ }^{33}$ Bozeman et al., ${ }^{34}$ and Rahimi et al., ${ }^{35}$ when MTA is placed in moist conditions it precipitates hydroxyapatite crystals on its surface. These hydroxyapatite crystals undergo nucleation and grow to fill in the gaps and spaces between MTA and the dentinal wall. As time passes, the reaction between the hydroxyapatite layer of MTA and the tooth's dentine leads to the formation of a chemical bond resulting in the formation of an apical seal at the MTA-dentine interface.

The findings of our study can be correlated well with those of Neekofar et al., ${ }^{36}$ Ustun et al., ${ }^{37}$ Ratih and Putri, ${ }^{38}$ and Subramanyam and Vasanthrajan. ${ }^{39}$ According to them, an interfacial gap created between MTA and radicular dentine in the presence of blood is because of air entrainment caused by hemoglobin and blood proteins like albumin which not only have adverse effects on marginal adaptability but also create porous voids, thus reducing the sealability of MTA and disocclusion of MTA and dentinal tubules.

The reason for better marginal adaptation of MTA in presence of artificial salivary contamination can be attributed to the fact that, since saliva is a phosphate-containing fluid, it interacts with MTA to form carbonated apatite on its surface similar to the moisture content in the blood. This can be conferred from the findings of Tay et al. ${ }^{40}$ who suggested that calcium and hydroxyl ions are leached through outward diffusion from set Portland cements which creates a condition wherein calcium ions are continuously released to an environment of high alkalinity.

The results of our study were congruent with Gondim et al. ${ }^{41}$ where ProRoot MTA exhibited better sealing ability when compared 
with Super-EBA and IRM. Harmoniously Bidar et al. ${ }^{42}$ found that gray MTA showed better marginal adaptation than Portland cement and white MTA in decreasing order. A rapport to our study was found with Sanchez et al. ${ }^{43}$ and Saini et al. ${ }^{44}$ who found MTA to be close to an ideal root retro filling material in periapical surgery. The findings of Nekoofar et al. ${ }^{45}$ were consistent with ours, who proposed that blood had a detrimental effect on MTA and suggested hemorrhage control in the surgical area if MTA was to be used.

Unanimously Hindlekar and Raghavendra ${ }^{46}$ revealed that biodentine and MTA, both had similar sealing ability when compared with a lower seal produced by injectable GIC in blood and saliva contaminated cavities.

However, the results of the present study were in contrast with Montellano et al. ${ }^{47}$ who performed a bacterial penetration study and found that contaminated tooth-colored MTA leaked more in the presence of saliva over their 30 day time interval. In another dissimilar study, Hasheminia et al. ${ }^{48}$ compared the sealing ability of MTA with CEM and found CEM to be a more effective root-end sealant than MTA. Also, Ayatollahi et al. ${ }^{49}$ concluded that CEM cement in dry and saliva contaminated canals provided a significantly better seal as compared to MTA.

In another neoteric study, Pandey et al. ${ }^{50}$ comparatively evaluated the microleakage of MTA and Geristore in dry, saliva, and blood-contaminated environments and found Geristore equally effective as MTA in a dry environment but provided a better apical seal than MTA in saliva and blood-contaminated environments.

\section{ConcLusion}

Mineral trioxide aggregate, being hydrophilic, can be manipulated using Ringer's lactate and Tetraspan. However, the presence of blood contamination at the junction of retrofilled MTA and root dentine had an unfavorable outcome in marginal adaptability of MTA when compared with artificial salivary contamination. Tetraspan, a hydroxyl ethyl starch (HES) containing intravenous fluid has a colloidal nature. Due to this fact, increased gap width and gap perimeter were observed at the MTA-dentine interface, especially in presence of blood than in presence of artificial saliva.

Our study was a bold and successful, ex vivo attempt to alter the original formulation of the liquid component of MTA. However, further in vivo studies need to be executed to confirm the findings of those obtained in our study.

\section{References}

1. Rao A, Rao A, Shenoy R. Mineral trioxide aggregate- a review. J Clin Pediatr Dent 2009;34(1):1-7. DOI: 10.17796/jcpd.34.1.n1t07578150 $67 g 83$.

2. Macwan C, Deshpande A. Mineral trioxide aggregate (MTA) in dentistry: a review of literature. J Oral Res Rev 2014;6(2):71-74. DOI: 10.4103/2249-4987.152914

3. Schwartz RS, Mauger M, Clement DJ, et al. Mineral trioxide aggregate: a new material for endodontics. J Am Dent Assoc 1999 Jul;130(7):967975. DOI: 10.14219/jada.archive.1999.0337.

4. Torabinejad M, Chivian N. Clinical applications of mineral trioxide aggregate. J Endod 1999;25(3):197-205. DOI: 10.1016/S00992399(99)80142-3.

5. Srinivasan $V$, Waterhouse $P$, Whitworth J. Mineral trioxide aggregate in paediatric sentistry. Int J Paediatr Dent 2009;19(1):34-37. DOI: 10.1111/j.1365-263X.2008.00959.x.

6. Bolhari B, Yazdi K, Sharifi F, et al. Comparative scanning electron microscopic study of the marginal adaptation of four root-end filling materials in presence and absence of blood. J Dent (Tehran) 2015;12(3):226-234.

7. Milani AS, Rahimi S, Frougheyhani M, et al. Effect of blood contamination on marginal adaptation and surface microstructure of mineral trioxide aggregate: a SEM study. J Dent Res Dent Clin Dent Prosp 2013;7(3):158-163.

8. Shipper G, Grossman ES, Botha AJ, et al. Marginal adaptation of mineral trioxide aggregate (MTA) compared with amalgam as a root-end filling material: a low-vacuum (LV) versus high-vacuum (HV) SEM study. Int Endod J 2004;37(5):325-336. DOI: 10.1111/j.01432885.2004.00806.x.

9. Chong BS, Pitt Ford TR, Watson RF. Sealing ability of potential retrograde root filling materials. Dent Traumatol 1995;11(6):264-269. DOI: 10.1111/j.1600-9657.1995.tb00501.x.

10. Taylor GN, Bump R. Endodontic considerations associated with periapical surgery. Oral Surg Oral Med Oral Pathol 1984;58(4):450455. DOI: 10.1016/0030-4220(84)90343-8.

11. Gutmann JL, Gutmann MS. Historical perspectives on the evolution of surgical procedures in endodontics. J Hist Dent 2010;58(1):1-42.

12. Torabinejad M, Higa RK, McKendry DJ, et al. Dye leakage of four root end filling materials: effects of blood contamination. J Endod 1994;20(4):159-163. DOI: 10.1016/S0099-2399(06)80326-2.

13. Kokate S, Pawar A. An in vitro comparative stereomicroscopic evaluation of marginal seal between MTA, glass ionomer cement \& biodentine as root end filling materials using $1 \%$ methylene blue as tracer. Endodontology 2012;24:36-42.

14. Gutmann JL. Surgical endodontics: past, present, and future. Endodon Top 2014;30(1):29-43. DOI: 10.1111/etp.12058.

15. Gilheany PA, Figdor D, Tyas MJ. Apical dentin permeability and microleakage associated with root end resection and retrograde filling. J Endod 1994;20(1):22-26. DOI: 10.1016/s0099-2399(06)80022-1.

16. Bates CF, Carnes DL, del Rio CE. Longitudinal sealing ability of mineral trioxide aggregate as a root-end filling material. J Endod 1996;22(11):575-578. DOI: 10.1016/S0099-2399(96)80023-9.

17. Gagliani M, Taschieri S, Molinari R. Ultrasonic root-end preparation: influence of cutting angle on apical seal. J Endod 1998;24(11):726-730. DOI: 10.1016/S0099-2399(98)80162-3.

18. Malhotra S, Hegde MN. Analysis of marginal seal of ProRoot MTA, MTA Angelus biodentine and glass ionomer cement as root-end filling materials: an in vitro study. J Oral Res Rev 2015;7(2):44-49. DOI: 10.4103/2249-4987.172493.

19. Torabinejad M, Hong CU, Lee SJ, et al. Investigation of mineral trioxide aggregate for root-end filling in dogs. J Endod 1995;21(12):603-608. DOI: 10.1016/S0099-2399(06)81112-X.

20. Hargreaves KM, Cohen S, Berman LH. Cohen's pathways of the pulp. 10th ed., Elsevier/Mosby; 2011. pp. 720-776.

21. Torabinejad M. Chemical properties of MTA. In: Torabinejad M. Properties and clinical applications. 1st ed., Munksgard: John Wiley and Sons, Inc. Blackwell; 2014. pp. 17-36.

22. Belio-Reyes IA, Bucio L, Cruz-Chavez E. Phase composition of ProRoot mineral trioxide aggregate by X-ray powder diffraction. J Endod 2009;35(6):875-878. DOI: 10.1016/j.joen.2009.03.004.

23. Machado D, Bertassoni L, de Souza $E$, et al. Effect of additives on the compressive strength and setting time of a Portland cement. Braz Oral Res 2010;24(2):158-164. DOI: 10.1590/s1806-83242010000200006.

24. Kogan P, He J, Glickman GN, et al. The effects of various additives on setting properties of MTA. J Endod 2006;32(6):569-572. DOI: 10.1016/j. joen.2005.08.006.

25. https://www.bbraun.ph/content/dam/catalog/bbraun/ bbraunProductCatalog/S/AEM2015/en-ph/b/15242872-1112lactatedringerssolution.pdf.bb-.39375847/15242872-1112lactatedringerssolution.pdf.

26. Karnik HS. Fluid management in infants and children during intracranial surgery. J Neuroanaesthesiol Crit Care 2017;4(04):S24S29. DOI: 10.4103/2348-0548.199945.

27. Hasheminia SM, Nejad SL, Dianat O, et al. Comparing the sealing properties of mineral trioxide aggregate and an experimental 
ceramic based root end filling material in different environments. Indian J Dent Res 2013;24(4):474-477. DOI: 10.4103/0970-9290.118399.

28. Orucoglu H, Sengun A, Yilmaz N. Apical leakage of resin based root canal sealers with a new computerized fluid filtration meter. J Endod 2005;31(12):886-890. DOI: 10.1097/01.don.0000164134.79052.b3.

29. Orosco FA, Bramante CM, Garcia RB, et al. Sealing ability, marginal adaptation and their correlation using three root-end filling materials as apical plugs. J Appl Oral Sci 2010;18(2):127-134. DOI: 10.1590/s167877572010000200006.

30. Mattison GD, Fraunhofer A, Delivanis PD, et al. Microleakage of retrograde amalgams. J Endod 1985;11(8):340-345. DOI: 10.1016/ s0099-2399(85)80041-8.

31. Clay CS, Peace GW. lon beam sputtering: an improved method of metal coating SEM samples and shadowing CTEM samples. J Micros 1981;123(1):25-34. DOI: 10.1111/j.1365-2818.1981.tb01277.x.

32. Khalighinejad N, Barekatine B, Hasheminia SM, et al. In vitro evaluation of two methods of ultrasonic irrigation on marginal adaptation of MTA plugs in open apex teeth: a SEM analysis. Indian J Dent Res 2014;25(1):69-72. DOI: 10.4103/0970-9290.131132.

33. Sarkar NK, Caicedo R, Ritwik P, et al. Physicochemical basis of the biologic properties of mineral trioxide aggregate. J Endod 2005;32(2):97-100. DOI: 10.1097/01.don.0000133155.04468.41.

34. Bozeman TB, Lemon RR, Eleazer PD. Elemental analysis of crystal precipitate from gray and white MTA. J Endod 2006;32(5):425-428. DOI: 10.1016/j.joen.2005.08.009.

35. Rahimi S, Ghasemi N, Shahi S, et al. Effect of blood contamination on the retention characteristics of two endodontic biomaterials in simulated furcation perforations. J Endod 2013;39(5):697-700. DOI: 10.1016/j.joen.2013.01.002

36. Neekofar MH, Stone DF, Dummer PMH. The effect of blood contamination on the compressive strength and surface microstructure of mineral trioxide aggregate. Int Endod J 2010;43(9):782-791. DOI: 10.1111/j.1365-2591.2010.01745.x.

37. Ustun Y, Topcuoglu HS, Akpek F, et al. The effect of blood contamination on dislocation resistance of different endodontic reparative materials. J Oral Sci 2015;57(3):185-190. DOI: 10.2334/ josnusd.57.185.

38. Ratih DN, Putri AR. Effect of blood contamination on push-out bond strength of mineral trioxide aggregate mixed with different liquids. J Med Biolog Engineer 2017;37(2):262-267. DOI: 10.1007/s40846-0160199-8.

39. Subramanyam D, Vasanthrajan M. Effect of oral tissue fluids on compressive strength of MTA and biodentine: an in vitro study.
J Clin Diagn Res 2017;11(4):ZC94-ZC96. DOI: 10.7860/JCDR/2017/ 24510.9722.

40. Tay FR, Pashley DH, Rueggeberg FA, et al. Calcium phosphate phase transformation produced by the interaction of the Portland cement component of white mineral trioxide aggregate with a phosphatecontaining fluid. J Endod 2007;33(11):1347-1351. DOI: 10.1016/j. joen.2007.07.008.

41. Gondim E, Kim S, de Souza-Filho. F. An investigation of microleakage from root-end fillings in ultrasonic retrograde cavities with or without finishing: a quantitative analysis. Oral Surg Oral Med Oral Path Oral Radiol Endod 2005;99(6):755-760. DOI: 10.1016/j.tripleo.2004. 08.019.

42. Bidar M, Moradi S, Jafarzadeh $\mathrm{H}$, et al. Comparative SEM study of the marginal adaptation of white and grey MTA and Portland cement. Aust Endod J 2007;33(1):2-6. DOI: 10.1111/j.1747-4477.2007. 00053.x.

43. Sanchez AF, Berrocal IL, Gonzalez JM. Metaanalysis of filler materials in periapical surgery. Med Oral Patol Oral Cir Bucal 2008;13(3):E180E185.

44. Saini D, Nadig G, Saini R. A comparative analysis of microleakage of three root end filling materials - an in vitro study. Archiv Ororfac Sci 2008;3(2):43-47.

45. Nekoofar MH, Oloomi K, Sheykhrezae MS, et al. An evaluation of the effect of blood and human serum on the surface microhardness and surface microstructure of mineral trioxide aggregate. Int Endod J 2010;43(10):849-858. DOI: 10.1111/j.1365-2591.2010.01750.x.

46. Hindlekar A, Raghavendra SS. Comparative evaluation of sealing ability of three root-end filling materials- an in vitro study. Int J Dent Clin 2014;6(4):4-7.

47. Montellano AM, Schwartz SA, Beeson TJ. Contamination of toothcolored mineral trioxide aggregate used as a root-end filling material: a bacterial leakage study. J Endod 2006;32(5):452-455. DOI: 10.1016/j. joen.2005.07.001.

48. Hasheminia M, Nejad SL, Asgary S. Sealing ability of MTA and CEM cement as root-end fillings of human teeth in dry, saliva or bloodcontaminated conditions. Iran Endod J 2010;5(4):151-156.

49. Ayatollahi F, Tabrizizadeh M, Abad MHB, et al. Comparison of microleakage of MTA and CEM cement apical plugs in three different media. Iran Endod J 2016;11(3):198-201. DOI: 10.7508/iej.2016.03.010.

50. Pandey R, Dixit N, Dixit KK, et al. Comparative evaluation of microleakage of mineral trioxide aggregate and Geristore root-end filling materials in different environments: an in vitro study. J Conserv Dent 2018;21(3):328-332. DOI: 10.4103/JCD.JCD_333_17. 